\title{
COVID-19 and Dental Practice: A Review
}

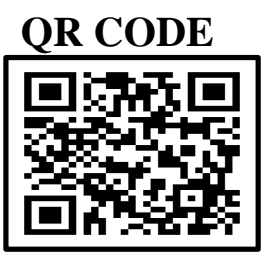

\section{SANA BASHIR D}

Novel coronavirus outbreak which started in Wuhan in December 2019 has spread across the globe at a high pace. This infection can be transmitted through droplets, close contacts, aerosols and other forms. Both uninfected patients and healthcare professionals are hesitating in seeing each other being scared of catching this viral disease. To overcome this upcoming gap between healthcare professionals and patients, there is a need to find out a way to answer their concerns and reinforce their confidence. As no specific treatment for this pandemic exists, one can only rely on infection control measures to prevent further spread of this disease. The aim of this review is to focus on specific guidelines in order to reduce the risk of COVID-19 transmission in dental clinics and hospitals.

KEYWORDS: COVID-19, Coronavirus, Dentistry

\section{INTRODUCTION}

Coronavirus pandemic that originated in Wuhan, China in December 2019 has brought the world to a standstill. It has impacted the financial status of not only individuals but also big countries. Not only businesses and transportation have been hampered, the daily needs are also going out of stock due to stopped or low production and difficulty in supply due to movement issues. The important concern is its negative effects on the health of the subjects who are even COVID negative. The patients with other medical or dental ailments are reluctant to visit hospitals or clinics because they are scared to get COVID-19 infection thinking that the doctor or his workplace might have come in contact with a coronavirus infected patient.

The vice-versa also holds true. Private practitioners are not entertaining patients especially those who are down with flu like symptoms. Their feelings are genuine as this infection has high chances of transmission during medical or dental procedures. Research work has confirmed person to person transmission of the disease. ${ }^{1,2}$ Infection is transmitted by inhalation of large droplets generated during coughing, talking, or sneezing by both symptomatic and asymptomatic persons who are in a close range. Infection can also be acquired by touching surfaces contaminated by these droplets and then touching the nose, mouth, and eyes. ${ }^{3}$ Transmission through aerosols can also occur under specific circumstances such as tracheal intubation and extubation, noninvasive ventilation, manual ventilation before intubation, cardiopulmonary resuscitation, bronchoscopy, administration of high-flow oxygen or nebulized medications, tracheotomy and upper gastrointestinal endoscopy. ${ }^{4}$ The infected droplets can spread one to two meters and deposit on surfaces where it remains viable for a variable period. The virus was detectable up to four hours on copper, 24 hours on cardboard, and up to two to three days on plastics and stainless-steel surfaces. ${ }^{5}$ Healthcare professionals performing or assisting in aerosol generating procedures are at a very high risk of exposure.

The findings from a study indicate that the oral mucosa is an important vehicle for the COVID-19 infection transmission. ${ }^{6}$ Even though saliva can be delivered through cough, droplets can be emitted also through normal breathing 7 Therefore, viruses can be easily vehiculated by the aerosol generated by most of dental procedures. The dental staff should wash hands frequently, clean hands with alcoholic preparation before entering the operative area, follow social distancing and wear surgical masks, surgical cap, overshoes, disposable waterproof gown, protective goggles or full-face shield and gloves. During the dental procedures, extraoral $\mathrm{x}$-rays should be preferred, isolation with rubber dam should be done,

(c) Sana Bashir. This is an open access article distributed under the terms of the Creative Commons Attribution License CC-BY-NC 4.0, which permits unrestricted use, distribution and reproduction in any medium, provided the use is not commercial and the original author(s) and source are cited. 
aerosol making procedures should be avoided, high volume aspirating system should be used and disposable instruments should be preferred to the most possible extent. Furthermore, air purification and sanitization before and after dental procedures should be done. Disinfection of the whole clinic including reception areas, changing rooms and washrooms should be carried out every morning and evening even if no patient visits. In case of multiple patient, this needs to be implemented for maximum number of times possible, ideally after every patient.

Scheduled appointments should be fixed in such a manner that there is enough time gap between two patients, making disinfection of clinic and sterilization of the instruments possible. Time overlap should be strictly avoided for proper implementation of the sanitization protocol. Whole of the dental unit should be covered with disposable sheets that can be changed after every patient. In case of prosthodontic patients, the impression should be disinfected and sealed in an envelope before sending to lab. Care should be taken to avoid contamination of $\mathrm{x}$-ray envelopes, visiting cards, prescription slips and other stationery items. The patient should be directed to rinse the oral cavity with $1 \%$ hydrogen peroxide solution before every procedure.

Waste contaminated with blood, body fluids and secretions should be disposed of properly as per the local regulations. Single time use items should be discarded properly. Personal protective equipment kit has a very important role to play. All the dental staff including the assistants, hygienists, receptionist should wear the same. For more protection the patient should also be provided with such a kit. Accompanying persons should only be allowed in case of emergency, major dental procedure, pediatric patients and special cases like elderly and those who are medically or physically unfit. Before fixing an appointment, a detailed medical and travel history taking into account all symptoms of COVID-19 should be recorded and relevant associated questions should be asked via telephonic conversation.

In case of a recent travel to any foreign nation, the appointment should be re-scheduled. At the point of entry, thermal screening using contactless thermometer and hand sanitization of subjects entering the clinic should be done. In case of doubt, the regional health care authorities should be immediately intimated without any delay. Printed posters and standees should be pasted/placed in the dental office to instruct patients regarding standard respiratory hygiene recommendations and social distancing. ${ }^{8-10}$ It would be great if the patient leaves the clinic with more knowledge about preventive measures against coronavirus infection. All patients should be encouraged to download the Arogya Setu application. They should be told to further spread any important facts they have learned during their dental visit and inculcate hand and respiratory hygiene habits to protect themselves and their close ones from the frightful COVID-19 infection.

\section{CONCLUSION}

In the absence of specific therapy directed against the virus, it is of paramount importance to implement infection control practices by controlling the source of infection, blocking the route of transmission, and protecting the susceptible population. Prevention involves strict infection control measures at clinics that include contact and droplet precaution. The entire human race is eagerly waiting for some solution to this horrendous situation may be in the form of drugs or vaccines. Until this happens, dental professionals need to take precautions and follow infection control protocol far beyond what they have been implementing prior to this pandemic.

\section{REFERENCES}

1. Chan JFW, Yuan S, Kok KH, To KKW, Chu H, Yang J, et al. A familial cluster of pneumonia associated with the 2019 novel coronavirus indicating personto-person transmission: a study of a family cluster. Lancet. 2020;395(10223):514-23.

2. Cai J, Xu J, Lin D, Yang Z, Xu L, Qu Z, et al. A case series of children with 2019 novel coronavirus infection: clinical and epidemiological features. Clin Infect Dis. 2020 Feb 28; ciaa 198.

3. Singhal T. A review of coronavirus disease-2019 (COVID-19). Indian J Pediatr. 2020;87(4):281-6

4. Omer SB, Malani P, Del Rio C. The COVID-19 pandemic in the US: a clinical update. JAMA. $2020 \mathrm{Apr}$ 6.

5. van Doremalen $\mathrm{N}$, Bushmaker $\mathrm{T}$, Morris $\mathrm{DH}$, Holbrook MG, Gamble A, Williamson BN, et al. Aerosol and surface stability of SARS-CoV-2 as compared with SARS-CoV-1. N Engl J Med. 2020 Apr16;382(16):1564-7.

6. Xu H, Zhong L, Deng J, Peng J, Dan H et al. High expression of $\mathrm{ACE}_{2}$ receptor of $2019-\mathrm{nCoV}$ on the epithelial cells of oral mucosa. Int J Oral Sci. 2020;12:8. https://doi.org/10.1038/s41368-020-0074-x. 
7. Yan J, Grantham M, Pantelic J, et al. Consortium Infectious virus in exhaled breath of symptomatic seasonal influenza cases from a college community. Proc Natl Acad Sci. USA 2018; 115:1081-6. doi: 10.1073/pnas.1716561115.

8. Centers for Disease Control and Prevention. https://www.cdc.gov/coronavirus/2019- ncov/downloads/stop-the-spread-of-germs.pdf [Last accessed on June 25th, 2020].

9. Centers for Disease Control and Prevention. https://www.cdc.gov/oralhealth/infectioncontrol $\langle$ pdf/safe- care2.pdf [Last accessed on June 25th, 2020]. 10. Centers for Disease Control and Prevention. https://www.cdc.gov/coronavirus/2019-ncov/php/riskassessment.htm [Last accessed on June 25th, 2020]. 